nhỏ và thời gian nghiên cứu cần kéo dài hơn, tuy nhiên bước đầu cũng đã xác định được kiểu gen bằng phương pháp real-time $P C R$, tỉ lệ kiểu gen và tần số alen, và mối liên quan có thể trên quần thể người Việt Nam.

\section{TÀI LIỆ THAM KHẢO}

1. Motulsky AG, Qi M. Pharmacogenetics, pharmacogenomics and ecogenetics. J Zhejiang $\begin{array}{lll} & \text { Univ Sci } \quad \text { B. } 2006 ; 7(2): 169-170 .\end{array}$ doi:10.1631/jzus.2006.B0169

2. Zhu $Y$, Shennan $M$, Reynolds $K K$, et al. Estimation of warfarin maintenance dose based on VKORC1 (-1639 G>A) and CYP2C9 genotypes. Clin Chem. 2007:53(7):1199-1205. doi:10.1373/clinchem.2006.078139

3. Caldwell MD, Berg RL, Zhang KQ, et al. Evaluation of Genetic Factors for Warfarin Dose Prediction. Clin Med Res. 2007;5(1):8-16. doi:10.3121/cmr.2007.724
4. Dean L. Warfarin Therapy and VKORC1 and CYP Genotype. In: Pratt VM, Scott SA Pirmohamed $M$, et al., eds. Medical Genetics Summaries. Bethesda (MD): National Center for Biotechnology Information (US); 2012. http://www.ncbi.nlm.nih.gov/books/NBK84174/. Accessed May 31, 2021.

5. Phạm Thi Thuỳ. Nghiên cứu tính đa hình gen CYP2C9, VKORC1 và liều thuốc chống đông kháng vitamin K ở bênh nhân thay van tim cơ hoc. 2021.

6. Pop TR, Vesa ŞC, Trifa AP, Crişan S, Buzoianu AD. An acenocoumarol dose algorithm based on a South-Eastern European population. Eur J Clin Pharmacol. doi:10.1007/s00228-013-1551-3

7. Qayyum A, Najmi MH, Mansoor $Q$, et al. Frequency of Common VKORC1 Polymorphisms and Their Impact on Warfarin Dose Requirement in Pakistani Population. Clin Appl Thromb Hemost. 2018;24(2):323-329.

doi:10.1177/1076029616680478

\title{
NGHIÊN CỨU KẾT QUẢ SÀNG LOC PHÂN NHÓM NGUY CƠ CAO BÊNH LÝ TIỀN SẢN GIÂTT BẰNG THUÂT TOÁN FMF BAYES TẠI BÊ̂NH VIỆN QUỐC TẾ THÁI HÒA
}

\section{TÓM TẮT}

Đặt vấn đề: Tiền sản giật (TSG) là một rối loạn đa hề thống gây ảnh hưởng $2 \%-5 \%$ thai kỳ̀, là bênh lý có nhiều biến chứng cho me và thai. Những ảnh hưởng này có thể đước thay đổi thông qua các mô hình dự báo và điêu trị dự phòng bệnh sớm giúp cải thiên kết cục thai kỳ. Mục tiêu nghiên cứu: Xác định tỷ lệ nhóm nguy cơ cao TSG theo thuật toán FMF Bayes của các thai phụ đến khám thai tại bệnh viện Quốc tế Thái Hòa và các yếu tố liên quan. Phương pháp nghiên cứu: Nghiên cứu cắt ngang trên 230 thai phu có tuổi thai 11 tuần đến 13 tuần 6 ngày đến khám thai tại bệnh viện Quốc tế Thái Hòa trong thời gian tháng 10/2020 đến tháng 4/2021. Tất cả các thai phụ đều được phỏng vấn, đo huyết áp động mach trung bình, đo Doppler đông mach tử cung trung bình và kết quá MoM PAPP-A. Dùng thuật FMF Bayes để tính nguy cơ TSG với ngưỡng cắt là $1 / 100$. Kết quả: Tỷ lệ nhóm nguy cơ cao TSG của các thai phụ đến khám thai tai bênh viên Quốc tế Thái Hòa là 11,6\%. Các yếu tố liên quan đến nhóm nguy cơ cao TSG có ý nghĩa thống kê như: Nhóm thai phụ có huyết áp tâm thu $>128 \mathrm{mmHg}$ (PR 7,4; KTC 95\%: 1,6-34,2) và

\footnotetext{
${ }^{1}$ Bệnh viện Quốc tế Thái Hòa

2Đai hoc Y Dươ TP.HCM

Chịu trách nhiếm chính: Võ Minh Tuấn

Email: vominhtuan@ump.edu.vn

Ngày nhận bài: 5.4.2021

Ngày phản biên khoa học: 26.5 .2021

Ngày duyệt bài: 8.6.2021
}

Huỳnh Thị Tuyết Mai ${ }^{1}$, Võ Minh Tuấn ${ }^{2}$ nhóm thai phụ có huyết áp tâm trương $>79 \mathrm{mmHg}$ (PR 8,5; KTC 95\%: 2,6- 28,4). Kết luân: Tâm soát nguy cơ tiền sản giật thường quy bằng thuật toán FMF Bayes cho tất cả thai phụ đến khám ở tuổi thai 11- 13 tuân 6 ngày, tư đó có kể hoach quản lý và điêuu trị dự phòng bằng aspirine liều thấp mỗi ngày sau tam cá nguyêt thứ nhất.

Tì̛ khóa: Tiền sản giật, Doppler động mạch tử cung, huyết áp trung bình.

\section{SUMMARY}

THE PREVALENCE OF SCREEN POSITIVE PRE-ECLAMPSIA AND ITS RISK FACTOR AT THAI HOA HOSPITAL

Background: Pre-eclampsia is a multisystem disorder affecting $2 \%-5 \%$ of pregnancies and is associated with multiple maternal and fetal complication. These effects an be altered through predictive models and early disease prevention, will improve pregnancy outcomes. Objective: to investigate the prevalence and relative factors of screen positive pre-eclampsia among pregnancies from Thai Hoa Hospital. Methods: Cross-section study of 230 pregnant women from 11 to 13 weeks 6 days of gestation who have antenatal care at Thai Hoa hospital, Đong Thap from October 2020 to April 2021. All pregnancies have measured value of mean arterial pressure, mean uterine artery PI and. serum PAPP-A was converted into MoM. Model-based estimates of screening performance using Bayes' theorem which the cut off points is $1 / 100$. Result: Survey of 230 samples has found that rate of screen positive pre- 
eclampsia is $11.6 \%$. Factors related to screen positive pre-eclampsia were statistically significant such as: systolic blood pressure $>128 \mathrm{mmHg}$ in the first trimester in the first trimester ( $P R=7.4 ; C I$ 95\%: 1.6$34.2)$ and diastolic pressure $>79 \mathrm{~mm} \mathrm{Hg}(P R=8.5 ; \mathrm{CI}$ 95\%: 2.6- 28.4) Conclusion: routine pre-eclampsia risk screening by FMF Bayes algorithm for all pregnance who come to the clinic at $11-13$ weeks and 6 days of gestation, from which a management plan and daily prophylaxis with low-dose aspirin beginning after the first trimester.

Key words: Pre-eclampsia (PE), mean arterial pressure (MAP), mean uterine artery PI (UtA).

\section{I. ĐĂT VẤN ĐỀ}

Tiền sản giật là một rối loạn đa hệ thống gây ảnh hưởng 2\%-5\% thai kì, là một bệnh lý có nhiều biến chứng cho me và thai, nguyên nhân hàng đầu làm tăng tỷ lệ tử vong và bệnh tật cho me và trẻ sơ sinh trên toàn thế giới, đặc biệt khi tình trạng bệnh lý này xuất hiện sớm trong thai kỳ [1].

Trong nhiều thập kỷ qua, các nghiên cứu trên thế giới tìm ra các mô hình sàng lọc sớm bệnh lý tiền sản giật có hiệu quả với mục tiêu xác định nhóm thai phụ có nguy cơ cao tiền sản giật để kịp thời áp dụng các biện pháp dự phòng và có chương trình quản lý thai kỳ chặt chẽ, phù hợp giúp giảm tỷ lệ xuất hiện bệnh cũng như các biến chứng nặng của bệnh.

Những năm gần đây, nhiều nghiên cứu cho thấy tầm soát tiền sản giật chỉ dựa vào một yếu tố duy nhất cho kết quả không cao bằng việc kết hợp nhiều yếu tô khác. Nghiên cứu của tác giả Poon cùng cộng sự thực hiện trên dân số Châu Á và thử nghiềm lâm sàng của Aspre đã cho thấy thuật toán FMF Bayes: kết hợp yếu tố mẹ, tiền sử sản khoa, sinh lý và sinh hóa cho kết quả tầm soát tiền sản giật lên đến 75,6\% [6].

Đồng Tháp là tỉnh Nam Bộ, nằm trong khu vực nhiệt đới gió mùa với hai mùa rõ rệt là mùa mưa và mùa nắng. Nghề nghiệp của phụ nữ chủ yếu là công việc liên quan đến lao động chân tay như làm nông, buôn bán và nôi trợ. Bênh viện Quốc tế Thái Hòa là bệnh viện tư nhân hạng II với quy mô 200 giường và được khám BHYT cho toàn tỉnh Đồng Tháp. Qua 10 năm hoạt động trong lĩnh vực chăm sóc sức khỏe cho người dân tại tỉnh Đồng Tháp, việc chăm sóc sức khỏe và quản lý thai nghén là chiến lược của bệnh viện Quốc tế Thái Hòa. Việc tầm soát tiền sản giật đã được thực hiện theo tiêu chuẩn NICE hay ACOG nhưng chưa có một quy trình tầm soát kết hợp nhiều yếu tố. Vì vậy, chúng tôi thực hiện "Nghiển cứu kết quả sàng lọc phân nhóm nguy cơ cao bệnh lý tiền sản giật bằng thuật toán FMF Bayes tại bệnh viên Quốc tế Thái Hòa" với câu hỏi nghiên cứu" Tỳ lệ nhóm nguy cơ cao tiền sản giật của các thai phụ đến khám tại bệnh viện Quốc tế Thái Hòa là bao nhiêu?".

\section{Mục tiêu nghiên cứu}

Mục tiêu chính: Xác định tỷ lệ nhóm nguy cơ cao tiền sản giật của các thai phụ đến khám tại Bệnh viện Quốc tế Thái Hòa, từ tháng 10 năm 2020 đến tháng 04 năm 2021.

Mục tiêu phụ: Khảo sát một số yếu tỗ liên quan trong mấu nghiên cứu với nhóm nguy cơ cao tiền sản giật.

\section{II. ĐốI TƯợNG VÀ PHƯƠNG PHÁP NGHIÊN CỨU}

Đối tượng nghiên cứu. Tất cả các thai phụ đến khám tại bệnh viện Quốc tế Thái Hòa trong thời gian 10/2020 đến 4/2021 đồng ý tham gia nghiên cứu.

Tiêu chuẩn nhận vào. Thai phụ $\geq 18$ tuổi, đơn thai với tuổi thai $11-13$ tuần 6 ngày và đồng ý tham gia nghiên cứu.

\section{Tiêu chuẩn loại trừ}

- Thai phụ không thể cung cấp thông tin đầy đủ do bất kỳ các lý do sau như bệnh nặng, bệnh tâm thân.

- Thai nhi có bất thường nặng được phát hiện lúc tầm soát.

- Không đồng ý làm Double test.

\section{Phương pháp nghiên cứu}

Thiết kế nghiên cứu: Nghiên cứu cắt ngang

Cỡ mẫu. Cỡ mẫu tính theo công thức tỷ lệ trong quần thể với độ chính xác tuyệt đối:

$$
N=\frac{Z_{1-\propto / 2}^{2} P(1-P)}{d^{2}}
$$

$\mathrm{Z}=1,96 ; \mathrm{a}=0,05 ; \mathrm{d}=0,05$; để có cõ̃ mẫu lớn nhất nên $\mathrm{d}=0,05 \rightarrow \mathrm{N}=229$.

Phương pháp lấy mẫu, biến số chính

Lấy mâu toàn bộ: tữ tháng 10/2020 đến tháng 04/2021, tất cả các thai phụ từ $11-13$ tuần 6 ngày, đến khám tại phòng khám sản bệnh viên Quốc tế Thái Hòa và thỏa tiêu chuẩn chọn mẩu cũng như không có tiêu chuẩn loại trừ đều được mời tham gia nghiên cứu.

Bước 1: Chuẩn bị dụng cụ

Bước 2: Sàng lọc và thu nhận đối tượng nghiên cứu.

Bước 3: Thông tin về nghiên cứu và cam kết để thai phụ ký cam kết đồng thuận tham gia nghiên cứu.

Bước 4: Tiến hành phỏng vấn bảng câu hỏi

Bước 5: Đo huyết áp động mạch trung bình

Bước 6: Đo Doppler động mạch tử cung

Bước 7: Trích kết quả PAPP-A trong kết quả double test 
Bước 8: Tính chỉ số nguy cơ TSG theo thuật toán FMF Bayes: khi chỉ số này $\geq 1 / 100$ được xem là nguy cơ cao TSG (biến số chính).

Thu thập và xử lý số liệu. Sau khi thu thập số liệu, chúng tôi tiến hành tổng hợp đưa vào thuật toán FMF Bayes, phân tích, xử lý số liệu và viết báo cáo. Các số liệu sẽ được nhập và xử lý số liệu bằng phần mềm SPSS 20.0. Phân tích gồm 2 bước: bước 1 mô tả và phân tích đơn biến, bước 2 dùng mô hình hồi quy đa biến nhằm kiểm soát yếu tố gây nhiễu để tính $P R$ hiệu chỉnh ( $\left.P R^{*}\right)$ cho các biến số. Các phép kiểm đều được thực hiện với độ tin cậy 95\%.

Giấy phép Y đức. Nghiên cứu này được thông qua bởi Hội đồng Đạo đức trong nghiển cứu $\mathrm{Y}$ sinh học Đại học Y Dược TP.HCM, số 682/HĐĐĐ-ĐHYD, ngày 12/10/2020.

\section{KẾT QUẢ NGHIÊN CỨU}

Trong thời gian nghiên cứu, chúng tôi thu nhận được 236 thai phụ, nhưng có 10 thai phụ không làm xét nghiệm double test mà chuyển sang NIPT và 4 thai phụ đồng ý làm thêm xét nghiệm PAPP-A. Cuối cùng chúng thôi ghi nhận được 230 sản phụ thực hiện đầy đủ quy trình nghiên cứu.

1. Phân bố các yếu tố trong thuật toán FMF Bayes

Bảng 1: Phân bố các yêu tố trong thuật toán FMF Bayes

\begin{tabular}{|c|c|c|}
\hline Yếu tố & $\begin{array}{c}\text { Số } \\
\text { Iượng }\end{array}$ & $\begin{array}{c}\text { Tỷ lệ } \\
\text { (\%) }\end{array}$ \\
\hline $\begin{array}{c}\text { Loại thai } \\
\text { Đợn thai } \\
\text { Đặc điểm thai phù } \\
\text { Tuổi me (>35 tuổi) }\end{array}$ & 230 & 100 \\
\hline BMI (thữa cân- béo phi) & 37 & 16,1 \\
\hline
\end{tabular}

\begin{tabular}{|c|c|c|}
\hline Chủng tôc (Đông Á) & 230 & 100 \\
\hline Hút thuốc lá & 3 & 1,3 \\
\hline Tiền sử me TSG & 0 & 0 \\
\hline Thụ thai tự nhiên & 229 & 99,6 \\
\hline Tiền sử bản thân & & \\
\hline Cao huyết áp mãn & 5 & 2,2 \\
\hline ĐTÐ type I & 0 & 0 \\
\hline ĐTÐ type II & 0 & 0 \\
\hline Lupus ban đó hệ thống & 0 & 0 \\
\hline $\begin{array}{l}\text { Kháng phospholipid } \\
\text { Tiến sử sản khoa }\end{array}$ & 0 & 0 \\
\hline Con so & 93 & 40,4 \\
\hline Con rạ & 137 & 59,6 \\
\hline Khoảng cách sanh $\geq 10$ năm & 28 & 20,4 \\
\hline Tiền sử TSG & 4 & 2,9 \\
\hline Sinh con đủ tháng & 127 & 94,1 \\
\hline HA ĐMTB $(\geq 86,67)$ & 68 & 29,6 \\
\hline UtA-PI trung bình $(\geq 1,74)$ & 131 & 57 \\
\hline $\begin{array}{l}\text { ChI so sinn noa } \\
\text { PAPP-A MoM }(<0,52)\end{array}$ & 43 & 18,7 \\
\hline
\end{tabular}

2. Tỷ lệ nhóm nguy cơ cao tiền sản giật

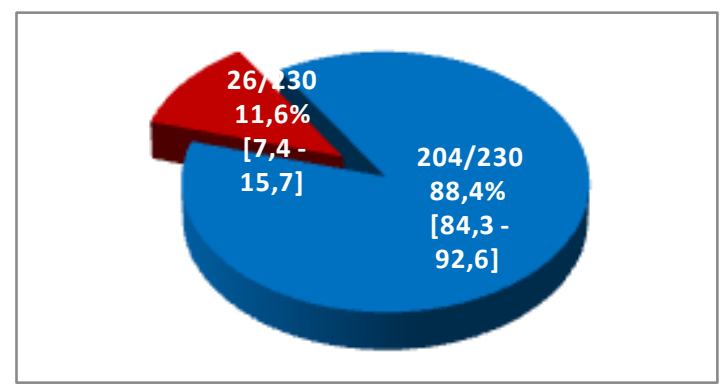

Biểu đồ 1: Phân bố tỷ lệ nhóm nguy cơ cao TSG Nhận xét: Trong tổng số 230 thai phụ tham gia đầy đủ nghiên cứu, có 26 thai phụ có nguy cơ cao tiền sản giật, chiếm tỷ lệ $11,6 \%$ [KTC 95\%: 7,4-15,7].

\section{Tỷ lệ sàng lọc dương nhóm nguy cơ cao tiên sản giật}

\section{Bảng 2: Tỷ lệ sàng loc dương nhóm nguy cơ cao tiên sản giật}

\begin{tabular}{|c|c|c|c|c|}
\hline Tác giả- Năm & $\begin{array}{c}\text { Mâu } \\
\text { nghiên cứu }\end{array}$ & Địa điểm nghiên cứu & $\begin{array}{c}\text { Đối tượng } \\
\text { nghiên cứu }\end{array}$ & $\begin{array}{l}\text { Tỷ lề } \\
(\%)\end{array}$ \\
\hline Liona $\mathrm{C}$ & 7.797 & Anh Quốc & Đơn thai & $6,1 \%$ \\
\hline M. Y. Tan (2018) [8] & 6.174 & Anh $C$ & Đơn & $10 \%$ \\
\hline Nguyê̂n Bích Chi (2020) [3] & 3.317 & $\begin{array}{l}\text { Khoa phụ sản trường ĐHYD Huế } \\
\text { Trung Tâm Y Học Di Truyền }\end{array}$ & Đơn thai & $18,2 \%$ \\
\hline $\begin{array}{l}\text { Trần Mạnh Linh (2020) [4] } \\
\text { Chúng tôi (2021) }\end{array}$ & $\begin{array}{c}400 \\
1.894 \\
230\end{array}$ & $\begin{array}{l}\text { sinh hơc phân tử miền nam } \\
\text { Bệnh viện trường ĐHYD Huế } \\
\text { Bệnh viện Quốc tế Thái Hòa }\end{array}$ & $\begin{array}{l}\text { Đơn Thai } \\
\text { Đơn thai } \\
\text { Đơn thai }\end{array}$ & $\begin{array}{l}5,5 \% \\
21,9 \% \\
11.3 \%\end{array}$ \\
\hline
\end{tabular}

\section{Phân tích yếu tố liên quan}

Sau khi phân tích đơn biến, chúng tôi ghi nhận được 3 yếu tố làm tăng tỷ số chênh PR nguy cơ cao tiền sản giật, tuy nhiên những yếu tố này có thể bị ảnh hưởng bởi các yếu tố gây nhiễu. Và để khống chế yếu tố gây nhiễu này, chúng tôi tiến hành phân tích hồi quy đa biến giữa nguy cơ cao TSG với các yếu tố, trong đó có 3 yếu tố độc lập nêu trên cùng với 3 yễu tố có $P \leq 0,2$. 
Bảng 3: Liên quan giữa nhóm nguy cơ cao TSG và yêu tố nguy cơ

\begin{tabular}{|c|c|c|c|c|c|}
\hline Đặc điểm & $\begin{array}{c}\text { Nguy co cao } \\
\mathbf{N}=26(\%)\end{array}$ & $\begin{array}{l}\text { Nguy cơ thấp } \\
\mathrm{N}=204(\%)\end{array}$ & $\begin{array}{c}\text { PR } \\
\text { (KTC95\%) }\end{array}$ & $\begin{array}{c}\text { PR }^{*} \\
\text { (KTC95\%) }\end{array}$ & p* \\
\hline a chỉ: TP, thị xã & $19(13,5)$ & $122(86,5)$ & 1 & 1 & \\
\hline & $7(7,9)$ & $82(92,1)$ & $1,8(0,7-4,5)$ & $1,5(0,5-4,7)$ & 0,590 \\
\hline Frình độ học vấn: $\geq$ Cấp 2 & $2(10,2)$ & $193(79,8)$ & 1 & 1 & \\
\hline$\leq$ Cấp 1 & & & $3,2(0,9-10,8)$ & $4,2(0,9-21,1)$ & ,074 \\
\hline THA:Khôr & & & 1 & 1 & \\
\hline Có & $7,7)$ & & $1,6(1,2-2,3)$ & $1,7(0,6-4,9)$ & 0,347 \\
\hline ương: $\leq 79$ & & & 1 & 1 & \\
\hline$>79$ & $7,2)$ & & $18,4(7,2-46,9)$ & $8,5(2,6-28,4)$ & 0,000 \\
\hline hỉ số HA tâm thu: $\leq 128$ & 15 & $199(92,9)$ & 1 & & \\
\hline$>128$ & 8) & $5(31,2)$ & $29,2(8,9-95,1)$ & $7,4(1,6-34,2)$ & 0,011 \\
\hline 8 & & & 1 & 1 & \\
\hline$\geq 1.39$ & $25(14,1)$ & $159(85,9)$ & $6,8(0,9-52,2)$ & $8,3(0,9-79,2)$ & 0,065 \\
\hline
\end{tabular}

PR: hồi quy đơn biến

\section{BÀN LUẬN}

Qua nghiên cứu, chúng tôi tầm soát tiền sản giật cho 230 thai phụ ở tuổi thai 11-13 tuần 6 ngày tại bệnh viện Quốc tế Thái Hòa, chúng tôi ghi nhận tỷ lệ tầm soát dương tiền sản giật theo thuật toán FMF Bayes là 11,3\%. Kết quả này tương đồng với nghiên cứu tại Anh quốc M.Y. Tan [8] năm 2018 là 10\%. Tuy nhiên, tỷ lệ nhóm nguy cơ cao này lại rất khác so với một số nghiên cứu khác trong và ngoài nước. Tỷ lệ nhóm nguy cơ cao của nghiên cứu chúng tôi cao hơn so với nghiên cứu của tác giả Liona $C$. Poon [6] 6,1\%, Nguyễn Thị Bích Chi [ 3] 5,5\% và thấp hơn của tác giả Cao Ngọc Thành [2] 18,2\%và Trần Mạnh Linh [4] 21,9\%. Sự khác biệt này có thể do tác giả Liona C. Poon nghiên cứu trên nhiều đối tượng khác nhau chẳng hạn da trắng, da đen, ...mà yếu tố chủng tộc, điều kiện kinh tế có thể làm thay đổi tỷ lệ bệnh TSG. Trong thuật toán FMF Bayes, tính nguy cơ TSG dựa trên các yếu tố me, gia đình, MAP, PI, PLGF và hoặc hay PAPP-A. Chúng tôi chọn PAPP-A để đưa vào mô hình thuật toán FMF Bayes thay vì PLGF hay cả hai chủ yếu do xét về tính kinh tế, vì thế nếu sử dung PAPP-A sẽ cho tỷ lề tầm soát dương cao hơn trong mô hình sử dụng PLGF một phần để nâng cao hiệu quả sàng lọc, tránh bỏ sót. Và đó là lý do có sự khác biệt với nghiên cứu của tác giả Nguyễn Thị Bích Chi cũng như nhóm tác giả Liona C. Poon So sánh với hai tác giả khác cùng thực hiện tại địa điểm nghiên cứu là bệnh viện Đại học $Y$ dược Huế, ho cũng chọn mô hình FMF Bayes, PAPP-A là chất chỉ điểm sinh hóa và có cùng ngưỡng cắt nguy cơ cao $>1 / 100$, nhưng các đặc điểm dân số nghiên cứu 2 nơi khác nhau như: trong nghiên cứu của tác giả Trần Mạnh Linh số thai phụ có hỗ trợ sinh sản, bệnh lý nền đái tháo đường thai kỳ, Lupus ban đỏ hệ thống, tiền sử mang thai TSG hay tiền sử gia đình có người bị TSG và trong nghiên cứu của chúng tôi không ghi nhận bệnh lý này hay nhiều nhất là một trường hợp. Đây là các yếu tố làm tăng nguy cơ cao tiền sản giật mà trong mô hình FMF có ghi nhận là biến số trong thuật toán FMF Bayes.

Từ những kết quả nêu trên, chúng tôi nhận thấy tỷ lệ nhóm nguy cơ cao tiền sản giật thay đổi tùy thuộc vào đặc điểm dân số nghiển cứu, điều kiện kinh tế xã hội, chủng tốc, tuổi và việc sử dụng các yếu tố nào để đưa vào mô hình tính nguy cơ cũng như ngưỡng cắt nguy cơ được xác định là bao nhiêu.

Trong nghiên cứu, chúng tôi chia huyết áp tâm trương của thai phụ thành 2 nhóm, trong đó nhóm thai phụ có huyết áp $>79 \mathrm{mmHg}$ chiếm $15,6 \%$. Sau khi tiến hành phân tích đơn biến và đa biến, chúng tôi nhận thấy rằng có mối liên quan giữa độ tuổi của thai phụ với đái tháo đường thai kỳ. Nhóm thai phụ $\geq 35$ tuổi làm tăng tỷ số chênh PR* nguy cơ TSG lên gấp 8,5 lần [KTC 95\% 2,6 - 28,4] so với nhóm thai phụ có huyết áp tâm trương $\leq 79 \mathrm{mmHg}$. Kết quả của nghiên cứu chúng tôi gần giống với kết quả của tác giả Duckitt [5] năm 2005 với PR* là 1,36 và tác giả Trần Mạnh Linh [4] năm 2020, huyết áp tâm trương, huyết áp tâm thu tại thời điểm 11 tuần - 13 tuần 6 ngày cao hơn có ý nghĩa ở nhóm thai kỳ có xuất hiện TSG sớm và muộn so với nhóm thai phụ không tăng HA.

Trong nghiên cứu của chúng tôi, nhóm thai phụ có huyết áp tâm thu $>128 \mathrm{mmHg}$ chiếm tỷ lệ $6,95 \%$. Sau khi phân tích hồi quy đơn biến và đưa vào phương trình hồi quy đa biến để kiểm soát yếu tố gây nhiễu, chúng tôi nhận thây rằng huyết áp tâm thu $>128 \mathrm{mmHg}$ ở tam cá nguyệt 
đầu là một yếu tố liên quan đến nguy cơ xuất hiện TSG. Nhóm thai phụ có huyết áp tâm thu > $128 \mathrm{mmHg}$ thì tỷ số chênh PR* nguy cơ TSG tăng gấp 7,4 lần [KTC 95\%: 1,6- 34,2] so với nhóm thai phụ có huyết áp tâm thu $\leq 128$ $\mathrm{mmHg}$. Kết quả này tương đồng với nghiên cứu của Sibal, huyết áp tâm thu có liên quan chặt chẽ với TSG với $P<0,001$ và tác giả Odegart ghi nhận huyết áp tâm thu $>130 \mathrm{mmHg}$ so với HA $<110 \mathrm{mmHg}$ trước 18 tuần làm tăng tỷ số $\mathrm{OR}$ TSG muộn 3,6 lần.

Tóm lại, nghiên cứu của chúng tôi cũng như nghiên cứu khác trong nước và trên thế giới, đều cho thấy có mối liên quan chặt chẽ giữa huyết áp tâm thu làm tăng tỷ số chênh PR nguy cơ cao TSG.

Hạn chế đề tài: đây là thiết kế cắt ngang không phải là thiết kế cho năng lực mẫu mạnh để khảo sát yếu tố liên quan

\section{KẾT LUẬN}

1. Tỷ lệ phân nhóm nguy cơ cao bệnh lý tiền sản giật của thai phụ đến khám thai tại bệnh viện Quốc Tế Thái Hòa là 11,6\%[KTC 95\%: 7,4 -15,7].

2. Các yếu tố liên quan đến nhóm nguy cơ cao tiền sản giật trong mẫu nghiên cứu ghi nhận được là:

- Thai phụ có huyết áp tâm thu cao hơn 128 $\mathrm{mmHg}$ trong 3 tháng đầu.

- Thai phụ có huyết áp tâm trương cao hơn 79 mmHg trong 3 tháng đầu.

Sử dụng thuật toán FMF Bayes sàng lọc sớm tiền sản giật thường qui cho tất các thai phụ 11 tuần đến 13 tuần 6 ngày đến khám thai tại bệnh viện. Từ đó có kế hoạch quản lý và điêu trị dự phòng sớm bằng aspirine liều thấp mỗi ngày cho nhóm đối tượng nguy cơ cao.

\section{TÀI LIÊU THAM KHẢO}

1. Bô môn Phư sản, Trường Đại học y dược TP. Hồ Chí Minh (2011). "Rối loạn cao huyết áp trong thai kỳ". Bài giảng Sản phụ khoa, tr. 462-477.

2. Cao Ngọc Thành, võ văn Đức, Nguyễn Vũ Quốc Huy (2015), "Mô hình sàng lọc bệnh lý tiên sản giật tại thời điểm 11 tuần đến 13 tuần 6 ngày thai kỳ dựa vào các yếu tố nguy cơ mè, huyết áp đông mạch trung bình, PAPP-A và siêu ầm doppler động mạch tử cung". Tạp chí phụ sản, 13 ( 3), tr. 38-46.

3. Nguyễn Bích Chi (2020). "Tỷ lệ dự đoán nguy cơ cao tiền sản giật trên thai phụ 11 tuần đến 13 tuần 6 ngày tại Trung Tâm $Y$ học di truyền sinh hoc phân tứ miền nam". Luân án chuyên khoa II chuyên ngành Sản phụ khoà- ĐH Y Dược Tp Hồ Chí Minh, Đại học y Dược TP.HCM.

4. Trân Mạnh Linh (2020). "Nghiên cứu kết quả sàng loc bênh lý tiền sản giật- sản giật bằng xét nghiệm PAPP- A, siêu âm doppler động mạch tử cung và hiệu quả điều trị dự phòng, Đại học y Dước Huế, tr.84-119.

5. Duckitt K., Harrington D. (2005). "Risk factors for pre-eclampsia at antenatal booking: systematic review of controlled studies". Bmj, 330 (7491), pp. 565

6. Poon L. C., Rolnik D. L., Tan M. Y., et al. (2018). "ASPRE trial: incidence of preterm preeclampsia in patients fulfilling ACOG and NICE criteria according to risk by FMF algorithm". Ultrasound Obstet Gynecol, 51 (6), pp. 738-742.

7. Roberge S., Bujold E., Nicolaides K. H. (2018). "Aspirin for the prevention of preterm and term preeclampsia: systematic review and metaanalysis". Am J Obstet Gynecol, 218 (3), pp. 287-293.

8. Tan M. Y., Syngelaki A., Poon L. C., et al. (2018). "Screening for pre-eclampsia by maternal factors and biomarkers at $11-13$ weeks' gestation". Ultrasound Obstet Gynecol, 52 (2), pp. 186-195

\section{NGHIÊN CỨU GÁNH NĂNG CHĂM SÓC BÊNH NHÂN PARKINSON CÓ SA SÚT TRÍ TUÊ BẰNG CHİ SỐ CĂNG THẲNG CHO NGƯờI CHĂM SÓC Có̉ SỬA ĐỔI}

\section{TÓM TẮT}

Mục tiêu: Đánh giá gánh nặng chăm sóc bệnh nhân Parkinson có sa sút trí tuệ bằng "Chỉ số cẳng thẳng cho người chăm sóc có sửa đổi" (MCSI Modified Caregiver Strain Index). Đối tượng và

*Trường Đại học Y Hà Nọi

Chịu trách nhiệm chính: Vi Ngọc Tuấn

Email: vituanhmu271295@gmail.com

Ngày nhận bài: 7.4.2021

Ngày phản biên khoa học: 24.5.2021

Ngày duyệt bài: 8.6.2021

\section{Vi Ngọc Tuấn*, Nguyễn Thanh Bình*}

phương pháp nghiên cứu: Nghiên cứu cắt ngang so sánh trên người chăm sóc chính của 100 bệnh nhân được chẩn đoán bênh Parkinson theo tiêu chuẩn của Ngân hàng não hội Parkinson Vương quốc Anh (UKPDSBB/United Kingdom Parkinson's Disease Society Brain Bank), nhóm bệnh nhân Parkinson có sa sút trí tuệ (SSTT) chẩn đoán theo tiêu chuẩn của Hiệp hội Tâm thân học Hoa Kỳ (DSM -V) tại Bệnh viện Lã̃o khoa Trung Ương từ tháng 06 năm 2020 đến tháng 05 năm 2021. Kết quả: 50 người chăm sóc chính của bênh nhân Parkinson không bị SSTT và 50 người chăm sóc chính bệnh nhân Parkinson có SSTT. Điểm MCSI của người chăm sóc trung bình là $9.73 \pm 7.558$. 